\title{
Interactive comment on "An Optimized Method for Determination of Water Soluble Organic Carbon and its Isotopic Composition in Aerosol Samples" by Wenqi Zhang et al.
}

\section{Anonymous Referee \#1}

Received and published: 9 March 2019

The manuscript reports an optimized method to analyze the $13 \mathrm{C}$ in the WSOC with small amounts, then applied it in the high time resolution aerosol samples during the haze period, and try to explain the source and processes beyond the variations of $\delta 13 \mathrm{C}-W S O C$. Although the context of this study does not introduce a bran-new method to analyze the carbon isotope or the new atmospheric process beyond what has been known, the optimized method will be a valuable contribution to the knowledge of WSOC. Overall, the manuscript is organized and read well. The paper does have a number of major issues that need to be addressed before publication. Major comments: 
(1) The manuscript set up an optimized method, and declare it is novel, but limited information for previous method (e.g. the theory, operation, use condition and deficiency...) present in the introduction section. Thus, the reader cannot get the challenge or difficulty for the establish of new method. Try to add the previous researches in the introduction, the challenge of the new method in the abstract, and the comparison in the discussion section.

Interactive

(2) Line 55-65: The isotope signatures of particulate matter (not the WSOC, or VOCs) emitted from different sources have limited the various of isotope signatures of $\delta 13 \mathrm{C}$ WSOC, due to the most part of the WSOC come from the secondary formation rather than the primary emission. In addition, the isotopic effects during the formation or aging process is absence of proof, need add some reference.

(3) The method needs to be explained much more clearly and in more detail, including the flow rate of $\mathrm{He}$, the volume of the bottle $(6 \mathrm{~mL}$ extraction for the $20 \mathrm{~mm}$ diameter disc, but how much for the TOC analysis, and how much use for the $\delta 13 \mathrm{C}$-WSOC analysis, if all use for $\delta 13 \mathrm{C}$-WSOC analysis, and another one for TOC, then the results in fig 4 need be reconsider due to the maldistribution in one filter), the volume of sample extracted solution, the ratio of sample extracted solution to the oxidizing agents....

(4) adjust the 2.4 and 2.5 section after 2.1 section

(5) The conversion efficiency (removal efficiency) showed be test, which is important to quality assurance of the $\delta 13 \mathrm{C}$-WSOC results. That is because there is fractionation during the conversion processes if the conversion efficiency is low, especially during a long reaction time. The operations of removal efficiency should cover two aspects: the residual WSOC in the reaction solution and the amount of $\mathrm{CO} 2$ in the bottle after heating, and compare them with the added WSOC.

(6) The IRMS method for WSOC concentration showed be present detail in the method section, rather than a single sentence like "Line 236 the peak area obtained from the measurement could represent the carbon content". If it means using the peak area

Printer-friendly version

Discussion paper 
represent the $\mathrm{CO} 2$ amounts in the inflow of IRMS? If yes, then show which peak use (10 peak total?), the gas volume in bottle and into IRMS (in the atm pressure, notice, the sample have different $\mathrm{C}$ content will product different amounts of $\mathrm{CO} 2$, and result in different pressure in the bottle), and the standard curve for the peak areaâĂ the bottle (or the WSOC, but need do the conversion efficiency test first).

Interactive

(7) How to explain the WSOC-IPMS method larger than the WSOC-TOC (fig 4)? And why some $30 \mu \mathrm{g}$-standard have the WSOC larger than $30 \mu \mathrm{g}$ ? Please reconsider (5) and (6).

(8) Line 206: the explain for the 13C-WSOC increase is kinetic isotope effect (KIE). This explanation is not reasonable because the leak process is fast and driven by strong motivation, which may not result in KIE. The mixture with $\mathrm{CO} 2$ in ambient air ( $-9 \%$ to $-7 \%$ o seems more reasonable. In addition, I agree the leak-sample will have a low WSOC content, but not all the leak-sample have a large $13 \mathrm{C}$ value showed in fig 2, for example, there are one $30 \mu \mathrm{g}$ standard sample have relatively lower WSOC content, but no significant difference between all the $30 \mu \mathrm{g}$ samples. Please explain.

(9) The final point bothers me is there are relatively large differences ( $3 \%$ o between the monocomponent standard samples with different WSOC content. Then for the complicated real aerosol samples, during each period, the 13C-WSOC changes ( $3 \%$ with WSOC content, how to evaluate the influence of WSOC content on the 13C-WSOC. If not evaluate, the conclusion for the source or transformation processes in each episode is lack of reliability

And there are some minor comments below point out areas that are not clear and make some suggestions.

Minor points:

Line 15-18 The difficulty for the method should be show

Line 23: give the real time resolution rather than using the "High time-resolved" 
Line 33: not all the dust carbonates are water-insoluble carbon

Line 61: depleted, not enriched

Line 84: Reference

Line 89: Reference

Interactive

Line 100-101: Reference, and show the representativeness for other standards.

comment

Line 104: the exact $\delta$ for each standard, rather than the range

Line 106: give the $C$ concentration (or the volume for the certain $C$ mass) of the solution, and the exact magnitude, rather than the range.

Line: 145 the size of the filters

Line142: When was the filter in 2015 measured?

Line 168iijžthe carbon content unit?

Line 206: the sentence is not clear. Line 328-335 I agree that the fractionation during the secondary formation would result in the deplete of $13 \mathrm{C}$ in products (WSOC) compared to remaining substrate (the remaining VOCs), but how it can explain the explain the $13 \mathrm{C}$ enrichment in WSOC compared to TC ?

Line 716: Table 1 is not cited in the text

Line 702: add the size of each bottle, the volume and of solution, the flow rate of He... in Fig 1

Line 725: add the real $\delta 13 \mathrm{C}-\mathrm{KHP}$ in Fig $2 \mathrm{~b}$, as a line

Line 728 and 738: Please unify the use of frame lines

Line 734: add the 1:1 line and the correlation line

Interactive comment on Atmos. Chem. Phys. Discuss., https://doi.org/10.5194/acp-2018-1056, 
2018.

ACPD

Interactive

comment

Printer-friendly version

Discussion paper

C5

(c) (i) 